\title{
The Fine Structure of the Mature Zoosporangium of Nowakowskiella profusa
}

\author{
By T. C. CHAMBERS, KATALIN MARKUS \\ AND L. G. WILLOUGHBY \\ The Botany School, University of Melbourne, Victoria, Australia
}

(Accepted for publication 17 August 1966)

\begin{abstract}
SUMMARY
The fine structure of the mature sporangium of Nowakowskiella profusa Karling (Chytridiales, Phycomycetes) is described. Deductions are made about the dehiscence mechanism and the nature of the zoospore. A striking feature of the zoospore is a conspicuous fibrous body immediately adjacent to the refractive globule. This body possibly represents a primitive photoreceptor organelle.
\end{abstract}

\section{INTRODUCTION}

A previous study on the fine structure of lower fungi (Chytridiales, Phycomycetes) featured Rhizophlyctis rosea, a monocentric species the whole thallus of which is converted into a single sporangium at maturity (Chambers \& Willoughby, 1964). The present paper is concerned with Nowakowskiella profusa, a polycentric species of the same order, the thallus of which takes the form of a rudimentary mycelium with rhizoids bearing a potentially unlimited number of sporangia. In both $R$. rosea and $N$. profusa dehiscence of the sporangia results in the release of large posteriorly uniflagellate zoospores.

\section{METHODS}

Taxonomic identity of the material studied. According to Sparrow (1960) Nowakowskiella profusa is only doubtfully distinct from $N$. elegans. However, examination of much material of both species in ecological studies indicates that a true separation can be made. In his original descriptions of $N$. profusa, Karling $(1941,1944)$ described exo-operculate material only, but our own observations (Willoughby, 1961) tend to suggest that the species comprises an overlapping series of morphological forms in which endo-operculate and even inoperculate dehiscences may also occur (see Figs. 1-3.) The material studied in the present work exhibited dehiscences of the latter two types only. Typical Nowakowskiella zoospores with a laterally orientated nuclear cap and large refractive globule were liberated on dehiscence (Fig. 4). Zoospores bearing several smaller globules in addition were also observed.

Origin and treatment of the material studied. The material was derived from an uncultivated soil sample from Rutherglen, Victoria, Australia. The sample was flooded with water and baited with small squares of MXXT/S 300 (waterproofed) Cellophane, a good cellulose source for the lower aquatic fungi. After 2 weeks of incubation at $20^{\circ}$ numerous young colonies of Nowakowskiella profusa bearing sporangia were present on the Cellophane, particularly along the free edges. Marginal strips of the sub- 
stratum were cut away, checked for the presence of the fungus, washed vigorously in clean water, and fixed in $2 \% \mathrm{KMnO}_{4}$ at $2^{\circ}$ for $25 \mathrm{~min}$. Attempts to fix in various osmium tetroxide solutions were unsuccessful. Dehydration, infiltration with methacrylate and orientation during embedding followed the methods previously described (Chambers \& Willoughby, 1964). Sections were cut with glass knives in a Porter-Blum microtome, stained with uranyl acetate for $90 \mathrm{~min}$. (Gibbons \& Grimstone, 1960) and examined in a Siemens Elmiskop I at $80 \mathrm{kV}$. Plate numbers with the figure explanations refer to plates stored in the electron-microscope laboratory, Botany School, University of Melbourne.

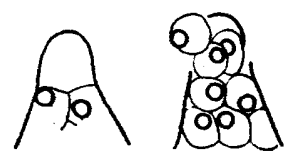

1
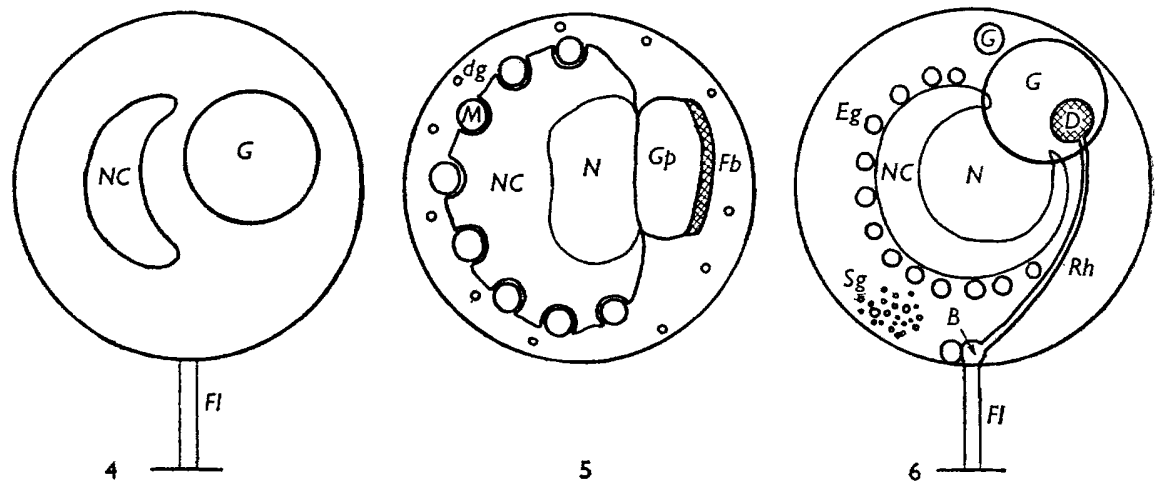

Figs. 1-6. Figs. 1-3: drawings of three types of dehiscence observed in Nowakowskiella profusa showing portions of mature and dehisced sporangia for each type: Fig. 1, exooperculate; Fig. 2, endo-operculate; Fig. 3. inoperculate. Gelatinous plug material at the exit tube apex is indicated by fine stippling in Figs. 2 and 3. Figs. 4, 5, 6: diagrammatic representations of a living zoospore of Nowakowskiella profusa as observed for Rutherglen material, a zoospore unit as deduced from the sections of mature sporangia, and the Nowakowskiella zoospore type as reconstructed by Koch, respectively. Fig. 6 is redrawn (by permission) from Koch's original papers, and for comparative interest the disc with grid substructure he reported for a Chytridium $\mathrm{sp}$. is transferred to it, in its correct position. $B$, blepharoplast; $D$, disc with grid substructure; $d g$, dark granule; $E g$, extranuclear granule (presumptive mitochondrion); $F b$, fibrous body; $F l$, flagellum; $G$, refractive globule; $G p$, presumptive refractive globule; $M$, mitochondrion; $N$, nucleus; $N C$, nuclear cap; $R h$, rhizoplast; $S g$, side granules.

\section{RESULTS}

The mature sporangium is divided into zoospore units, the approximate limits of which are readily apparent from the symmetrical groupings of the various organelles present (Pl. 1, fig. 1). In a typical median section of a sporangium between 20 and 25 zoospores are seen in various planes of sectioning, implying a total complement of about 40 . Zoospores are approximately $3 \mu$ across and their irregularity in outline is 
due to their packing within the sporangium. This is in accord with a slightly larger diameter of the zoospores after release from the sporangium, when they are perfectly spherical.

In section the sporangium wall, about $0.35 \mu$ wide overall, is composed of three distinct zones (Pl. 2, figs. 2, 3), the most conspicuous being the middle dense one which is about $0.2 \mu$ wide. The outer zone, at least $0.07 \mu$ wide, is rather diffuse and has the appearance of being easily sloughed off. It may well only represent the zone of partly dissolved cellulose bait. The inner zone is also about $0.07 \mu$ wide. It can be distinguished because there is a distinct layer of spongy material on its inner side. This spongy material, in addition to running beneath the sporangium wall, forms a continuous matrix between the cleaved zoospores and their flagella and extends in considerable quantity into the base of the dehiscence papilla. The particular dehiscence papilla illustrated in section (Pl. 2, fig. 3) is of the inoperculate type (see Fig. 3). The spongy material at its base is capped by a sharply defined dome of dense granular material. It appears that this effectively plugs the exit pore opening.

Provided the section is in a suitable plane each zoospore unit shows its conspicuous nucleus, bounded by a typical nuclear membrane (Pl. 4, fig. 5). Dense irregular masses of granular material are visible within it. Depending on the plane of the section, there is a tendency for the nucleus to have a flattened or even concave face and associated with this is often a very conspicuous clear region which may be up to $1.5 \mu$ across (Pl. 1, fig. 1; Pl. 3, fig. 4). This is presumed to correspond to the refractive globule of the living zoospore (Fig. 4). On the side of the clear region furthest from the nucleus there is a striking fibrous structure (Pl. 3, fig. 4; Pl. 4, fig. 5). In longitudinal section this structure which we are designating the fibrous body is seen to be made up of a series of cylindrical tubular elements each bounded at one end and on the sides by a clearly defined electron-dense margin - perhaps a membrane. The ends of the tubes on the outer side of the body against the cytoplasm are without such a defined margin (Pl. 5, fig. 6). Cross-sections of this fibrous structure indicate that the tubes are closely packed and circular in outline so that there are small inter-tubular spaces (P1. 5, fig. 7). Each tube is in contact with six neighbouring ones with a centre-to-centre distance of $45 \mathrm{~m} \mu$. On the side of the nucleus opposite to that occupied by the presumptive refractive globule there is a large densely granular mass which has considerable lateral extension. In certain sections, in fact, the nucleus appears to be totally embedded in it. This granular mass is taken to correspond to the nuclear cap of the living zoospore (Fig. 4). The nuclear cap, frequently reported for the zoospores of aquatic fungi, is generally assumed to represent a dense accumulation of ribosomal material (Blondel \& Turian, 1960).

Closely associated with the periphery of the nuclear cap and typically partially embedded in it are the mitochondria. Also associated with the periphery of the nuclear cap are occasional strands of endoplasmic reticulum and sometimes groups of small membrane-bounded electron-lucent regions. The nuclear cap is typically bounded from the cytoplasm by a definite double membrane (Pl. 3, fig. 4), and this is particularly apparent where the mitochondria abut on to it. In regions of the nuclear cap where the mitochondrial investment is lacking, however, so too may be the nuclear cap membrane (Pl. 4, fig. 5). The general cytoplasm of the zoospore is a loosely packed region, mottled in appearance. Embedded in it are Golgi dictyosomes, membranebounded dark granules and occasional short profiles of endoplasmic reticulum. The 
enveloping cell membrane is a very thin electron-dense structure sometimes appearing as two fine lines (Pl. 4, fig. 5). Between the zoospores, and suspended in the spongy material discussed above, are the flagella. These are seen in longitudinal section in Pl. 4, fig. 5 and in transverse section in Pl. 5, fig. 8.

\section{DISCUSSION}

Comparison of the fine structure of the mature sporangium of Nowakowskiella profusa with that of Rhizophlyctis rosea shows a common basic organization. Individual zoospores are distinguished together with their flagella, the whole compact structure being pervaded by the spongy ground material. In the case of $N$. profusa the disposition of this material in the dehiscence papilla region is especially interesting. It can be assumed that the dome of dense granular material observed capping it in the sections corresponds to the gelatinous plug material (Fig. 3) observed in living material. With the disappearance of this gelatinous plug material, which is diffluent, dehiscence ensues promptly. Clearly the zoospores emerge with (some even within) the spongy material of the papilla and their subsequent brief collective swarming before they finally disperse takes place in a vesicle transformed from it. Our observations then tend to suggest that the papillar material forming the physical basis for collective swarming is not some special tissue formed only in this region; rather it is merely an extension of similar material which is present throughout the whole sporangium.

In the mature sporangium of Rhizophlyctis rosea we reported a complex presumptive centriole described as 'extra-nuclear strands' immediately adjacent to the nucleus of the zoospore but in the present work with Nowakowskiella profusa no trace of any similar structure was observed. Instead we have to report another quite different and equally conspicuous structure closely associated with the nucleus (but separated from it by the refractive globule), namely the fibrous body. This is equated with the disc with grid substructure reported by Koch (1956) for zoospores of Chytridium sp. (Figs. 5, 6) from a study of shadowed electron-microscope preparations. Its possible function must be largely a matter for speculation, but since Koch demonstrated a rhizoplast thread joining it to the base of the flagellum, a connexion with the motility of the zoospore is strongly implied. In a search of the literature for anything similar, even remotely so, we have considered published figures of bands of cylindrical fibres connecting flagellar bases to the plastids in Prymnesium parvum (Manton \& Leedale, 1963), extensions of pharyngeal rods in Peranema trichophorum (Roth, 1959), and the honeycomb membrane between the shell and the cytoplasm in Gromia oviformis (Hedley \& Bertaud, 1962). A mechanical function is implied in the first two instances. Such a possibility is attractive; it might partly explain the origin of the peculiarly jerky and erratic movements of the chytrid zoospore flagellum. However, we have been advised (A. V. Grimstone, personal communication) that a direct connexion with motility is unlikely and that our fibrous body is reminiscent of a brush border. Bearing in mind that receptor organelles are commonly formed from such surface membranes our attention has been directed to the fine structure of the rhabdom in the eye of the lobster (Rutherford \& Horridge, 1965). This consists of enormous numbers of microvillar tubules, $60-100 \mathrm{~m} \mu$ in diameter. Microvillar receptors are apparently widely encountered in the invertebrates. Their arrangement in dense arrays is probably to give a large surface area to the photoreceptor and it is generally assumed that the 
photosensitive pigment lies in this region. If then we consider our fibrous body as a possible photoreceptor organelle, reports of Chytridiales zoospores which show phototactic reactions (cited in Sparrow, 1960) can be examined with renewed interest. The refractive globule of $N$. profusa might conceivably function as a lens. However, light microscopists have traditionally regarded it as lipid and primarily as providing a convenient high-energy source for the motile spore. Hints that this traditional view may be erroneous derive from the general conclusions of Koch (1958) that the refractive globule may have some direct role in the action of the flagellum, and from studies on Blastocladiella emersonii (Blastocladiales) by Cantino \& Lovett (1964). The latter have observed that zoospores of this species which swim and eventually disintegrate without the possibility of encystment and growth do not suffer depletion of their refractive globules. Carbohydrate available in the zoospore rather than the lipid is therefore proposed as the energy source. A past observation of our own may also bear recapitulation: when $N$. profusa zoospores germinate on nutrient agar their refractive globule is not lost; rather it persists apparently unchanged. In this case, however, it must be borne in mind that soluble carbohydrate from the medium would clearly constitute a more readily available energy source than a lipid zoospore inclusion. If the fibrous body in $N$. profusa is indeed a photoreceptor organelle its fine structure is of a much more definite and complex nature than the photoreceptor in Euglena spirogyra which is reported merely as a body of uniform electron density, except for some indication of fine striations (Leedale, Meeuse \& Pringsheim, 1965).

A point of interest concerning the nuclear cap is its close investment by the mitochondria, as reported by Koch $(1958,1961)$ for a Nowakowskiella sp. (Fig. 6) and also by Turian \& Kellenberger (1956) for Allomyces macrogynus. The accentuation of membranes where the mitochondria are in direct contact with the nuclear cap (there are actually eight consecutive parallel membranes across a line of $83 \mathrm{~m} \mu$ in the rectangle marked in Pl. 3, fig. 4) may be because of their importance in the intercellular translocation of small molecules (Frey-Wyssling, 1964). Finally the membranebounded dark granules are noted. These figured in our account of Rhizophlyctis rosea and were previously reported by Blondel \& Turian (1960) for A. macrogynus.

When our previous paper was written very few published studies on the fine structure of Phycomycete fungi were available. Studies by Cantino, Lovett, Leak \& Lythgoe (1963), Chapman \& Vujičić (1965), Fuller \& Reichle (1965), Goldstein, Moriber \& Hershenov (1964) and Renaud \& Swift (1964) must now be considered in any attempt to relate our findings to the development of the subject. It has already become commonplace to report the basic eucaryotic organelles such as membrane-bounded nuclei, mitochondria, etc., for these fungi. Accordingly, in the investigations cited above, emphasis has been placed on features of special interest, the uniqueness or otherwise of which it is difficult to evaluate at the present time. Cantino et al., for example, reported that in the zoospore of Blastocladiella emersonii there is a single huge mitochondrion attached by at least one banded rootlet to the flagellum. Chapman \& Vujicić, for Phytophthora erythroseptica, showed how the sporangium wall developed a prominent vesicular layer when the sporangium was destined to dehisce, but not when destined to germinate. Fuller \& Reichle, with Rhizidiomyces apophysatus, selected the presence of two centrioles in the zoospore as an unexpected attribute; apparently the single flagellum developed from only one of these. They also drew attention to membranebounded groups of fibres which may be essential for the development of wall material 
as the naked reproductive cell encysts and begins to germinate. Goldstein et al., for Thraustochytrium aureum, described peculiar mitochondria with concentric membranes enclosing cristae-free regions. Finally Renaud \& Swift, with Allomyces arbusculus, also demonstrated a paired centriole condition in the zoospore and made a detailed study of the ontogeny of the flagellum. In the present work with Nowakowskiella profusa, as in that on Rhizophlyctis rosea, some light has been thrown on the dehiscence mechanism in the Chytridiales and it seems unlikely that the dramatic preliminary fine structure changes reported for Phytophthora erythroseptica are involved. The extra-nuclear strands (centriole?) observed in Rhizophlyctis rosea cannot be equated very readily with the structures seen in $N$. profusa. The structural feature of special interest for the zoospore of $N$. profusa is the fibrous body; its true significance will only become apparent when studies on the fine structure and the biology of Phycomycete fungi are expanded further.

Our thanks are due to Professor J. S. Turner for encouragement to persevere with this project and to Mrs. C. Myers for photographic assistance. Dr A. V. Grimstone kindly advised us by correspondence. One of us (L. G. Willoughby) is indebted to the University of Melbourne for the award of a 1962-63 Senior Research Fellowship.

\section{REFERENCES}

Blondel, B. \& TURIAN, G. (1960). Relation between basophilia and fine structure of cytoplasm in the fungus Allomyces macrogynus Em. J. biophys. biochem. Cytol. 7, 127.

Cantino, E. C. \& LoveTt, J. S. (1964). Non-filamentous aquatic fungi: model systems for biochemical studies of morphological differentiation. Adv. Morphogen. $3,33$.

Cantino, E. C., Lovet,, J. S., Leak, L. V. \& LYThgoe, J. (1963). The single mitochondrion, fine structure and germination of the spore of Blastocladiella emersonii. J. gen. Microbiol. $31,393$.

Chambers, T. C. \& Willoughby, L. G. (1964). The fine structure of Rhizophlyctis rosea, a soil Phycomycete. $J l$ R. microsc. Soc. 83, 355.

Chapman, J. A. \& VuJIČIć, R. (1965). The fine structure of sporangia of Phytophthora erythroseptica Pethyb. J. gen. Microbiol. 41, 275.

Frey-Wyssling, A. (1964). Ultrastructural cell organelles. Proc. int. bot. Congr. $10,57$.

Fuller, M. S. \& ReICHLe, R. (1965). The zoospore and early development of Rhizidiomyces apophysatus. Mycologia 57, 946.

GibBons, I. R. \& Grimstone, A. V. (1960). On fiagellar structure in certain flagellates. J. biophys. biochem. Cytol. 7, 697.

Goldstein, S., Moriber, L. \& HeRshenov, B. (1964). Ultrastructure of Thraustochytrium aureum, a biflagellate marine Phycomycete. Mycologia 56, 897.

Hedley, R. H. \& BeRTAUd, W. S. (1962). Electron-microscopic observations of Gromia oviformis (Sarcodina). J. Protozool. 9, 79.

KARLING, J. S. (1941). Cylindrochytridium johnstonii gen.nov. et sp.nov., and Nowakowskiella profusum sp.nov. Bull. Torrey bot. Club 68, 381.

Karling, J. S. (1944). Brazilian Chytrids. I. Species of Nowakowskiella. Bull. Torrey bot. Club 71, 374.

KoCH, W. J. (1956). Studies of the motile cells of Chytrids. I. Electron microscope observations of the flagellum, blepharoplast and rhizoplast. Am. J. Bot. 43, 811.

KосH, W. J. (1958). Studies of the motile cells of Chytrids. II. Internal structure of the body observed with light microscopy. Am. J. Bot. 45, 59.

KосH, W. J. (1961). Studies of the motile cells of Chytrids. III. Major types. Am. J. Bot. 48, 786.

Leedale, G. F., Meeuse, B. J. D. \& Pringsheim, E. G. (1965). Structure and physiology of Euglena spirogyra. I and II. Arch. Mikrobiol. 50, 68.

Manton, I. \& Leedale, G. F. (1963). Observations on the fine structure of Prymnesium parvum Carter. Arch. Mikrobiol. 45, 285.

RENAUD, F. L. \& SwIFT, H. (1964). The development of basal bodies and fiagella in Allomyces arbusculus. J. Cell Biol. 23, 339.

RoTH, L. E. (1959). An electron-microscope study of the cytology of the protozoan Peranema trichophorum. J. Protozool. 6, 107. 


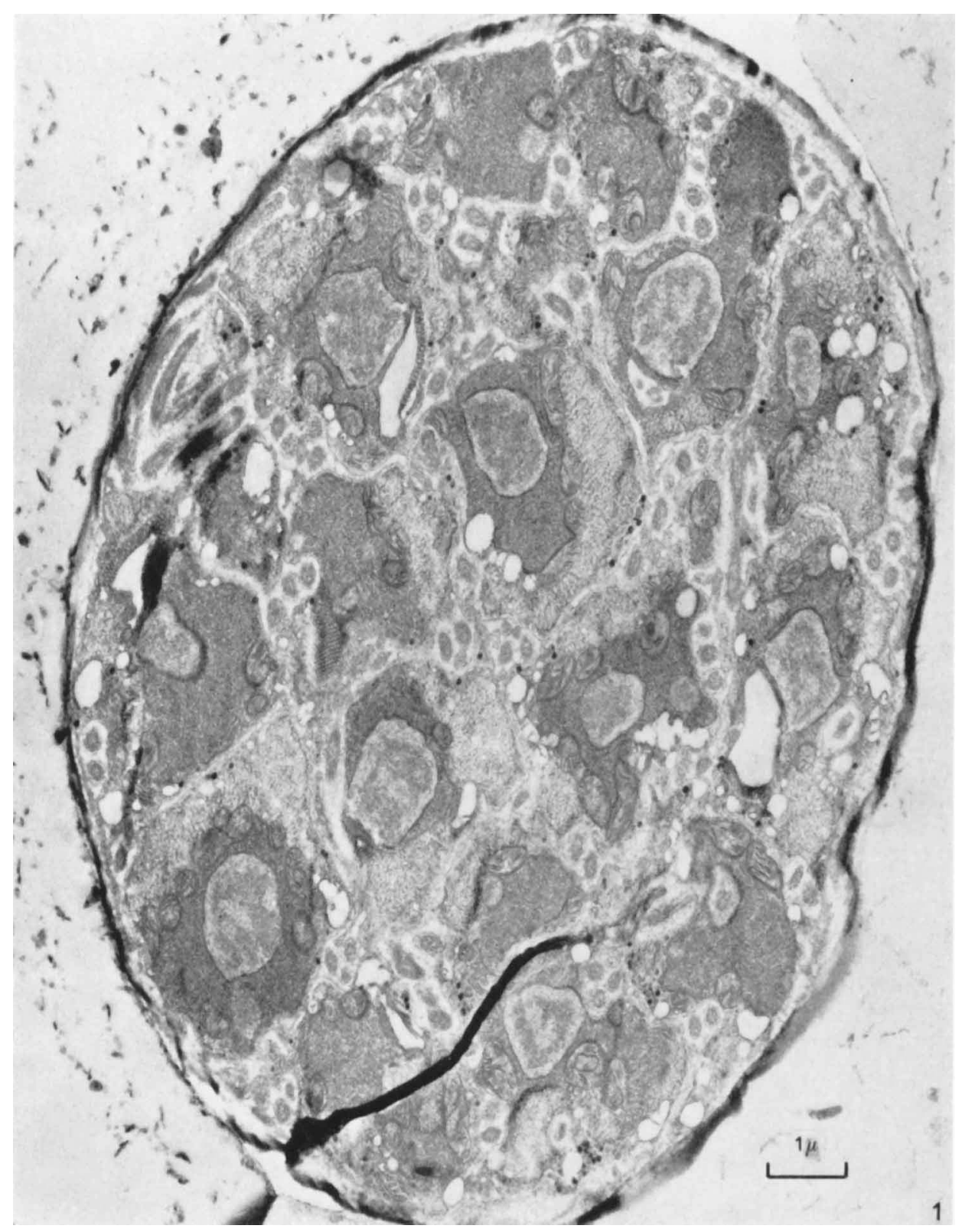




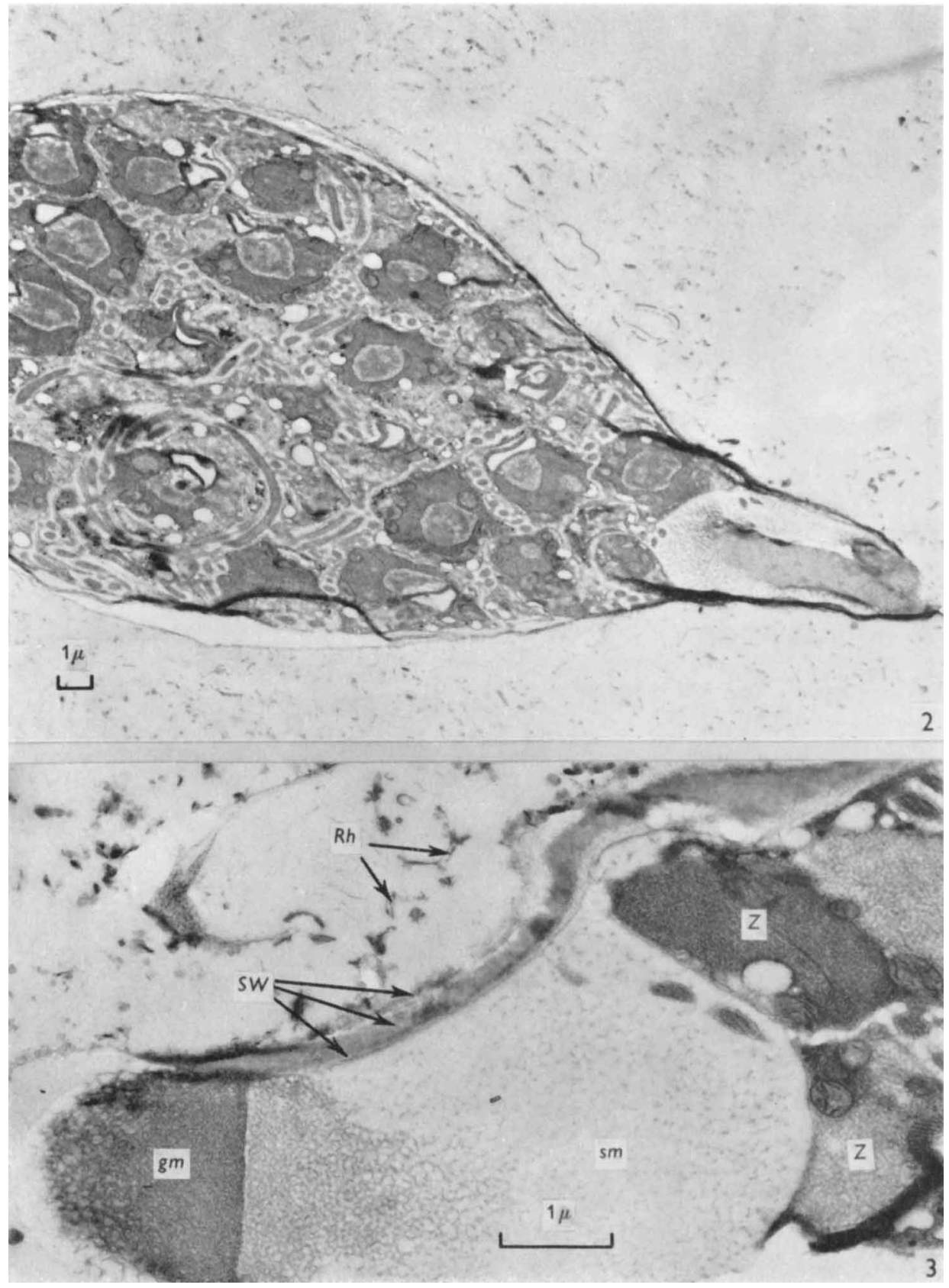

T. C. CHAMBERS, K. MARKUS AND L. G. WILLOUGHBY 


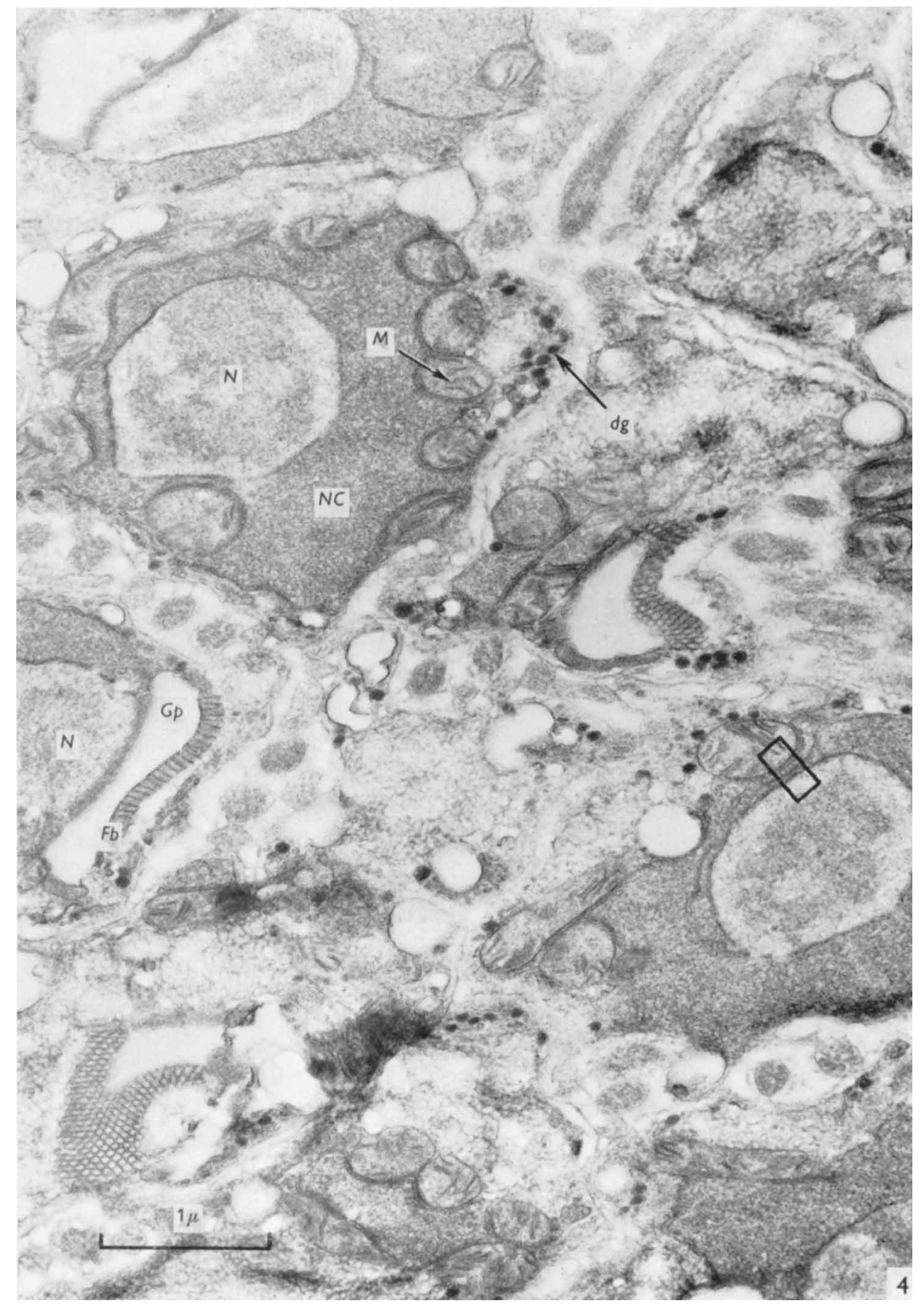

T. C. CHAMBERS, K. MARKUS AND L. G. WILLOUGHBY 


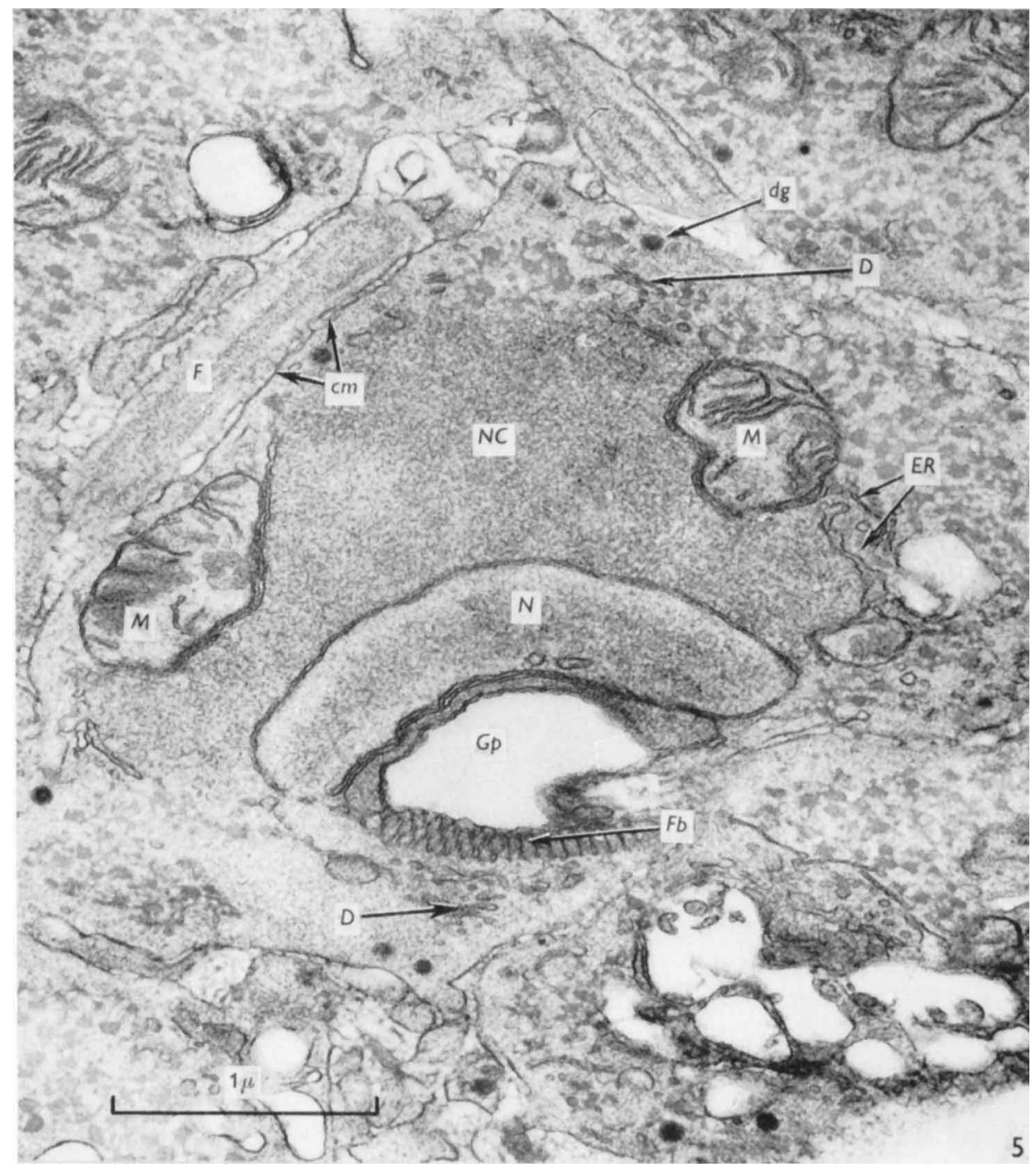



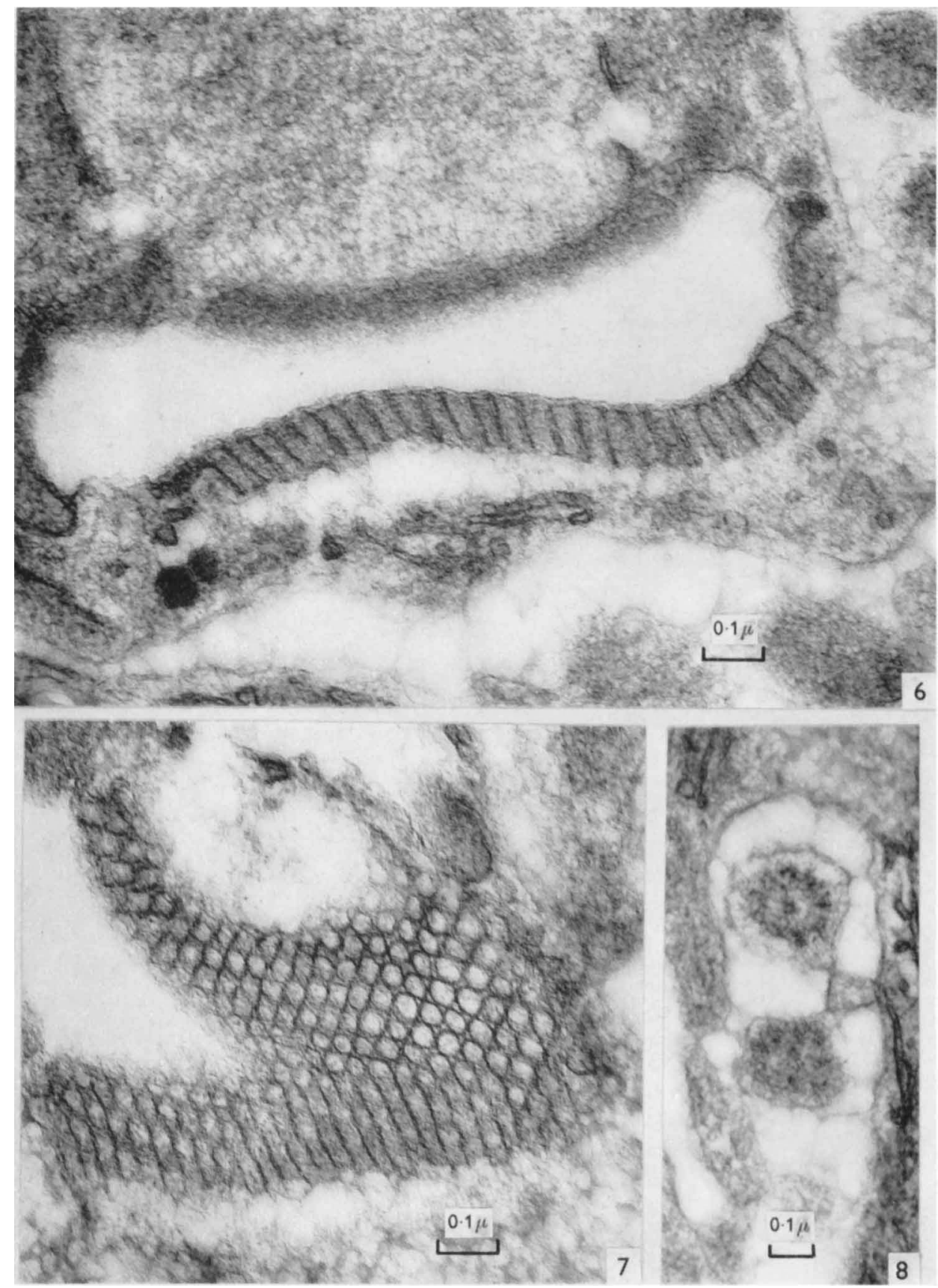

T. C. CHAMBERS, K. MARKUS AND L. G. WILLOUGHBY 
Rutherford, D. J. \& Horridge, G. A. (1965). The rhabdom of the lobster eye. Q. Jl microsc. Sci. $106,119$.

SpARROw, F. K. (1960). Aquatic Phycomycetes, 2nd. revised ed. Ann Arbor, U.S.A.: University of Michigan Press.

TURIAN, G. \& KellenBerger, E. (1956). Ultrastructure du corps paranucléaire, des mitochondries et de la membrane nucléaire des gamètes d'Allomyces macrogynus. Expl Cell Res. 11, 417.

Willoughby, L. G. (1961). The ecology of some lower fungi at Esthwaite Water. Trans. Br. mycol. Soc. 44, 305 .

\section{EXPLANATION OF PLATES}

\section{Plate 1}

Fig. 1. Median transverse section of a mature sporangium of Nowakowskiella profusa. The zoospores are each associated with a nucleus and nuclear cap material and in some the fibrous body is visible. The flagella, cut longitudinally, transversely and obliquely are wrapped around each zoospore and lie outside the cell membranes along the cleavage spaces between them. Fragments of poorly preserved rhizoid material are embedded in the surrounding Cellophane substratum. $\times 11,000(4000 \times 2.75)$. Pl. 7880.*

\section{Plate 2}

Fig. 2. Section of a sporangium of $N$. profusa in the plane of a dehiscence papilla. $\times 4400(2000 \times 2 \cdot 2)$. P1. 7885 .

Fig. 3. N. profusa. Details of a dehiscence papilla. Dense granular material $(\mathrm{gm})$ caps the spongy material $(s m)$ which is in contact with the zoospores $(Z)$. The sporangium wall $(S W)$ shows outer, middle and inner zones. Poorly preserved rhizoid material $(R h)$ is embedded in the Cellophane substratum. $\times 15,000(6000 \times 2 \cdot 5)$. Pl. 7927 .

\section{Plate 3}

Fig. 4. N. profusa. A small portion of a sporangium, showing details of several zoospores cut in different planes. Dark granules $(d g)$, fibrous bodies $(F b)$, presumptive refractive globules $(G p)$, mitochondria $(M)$, nuclei $(N)$, and nuclear caps $(N C)$ are distinguished throughout the section. The marked rectangle, referred to in the text, delimits an area with particularly numerous membranes. $\times 24,000(8000 \times 3)$. Pl. 7888 .

\section{Plate 4}

Fig. 5. N. profusa. A single zoospore with portions of others closely associated with its periphery. Flagella $(F)$ cut in longitudinal section are outside the cell membrane $(\mathrm{cm})$. The crescent-shaped nucleus $(N)$ lies above a membrane-bounded electron-lucent region, the presumptive refractive globule $(G p)$, and this in turn adjoins a concave plate of tubules, the fibrous body $(F b)$, sectioned longitudinally in this preparation. Above the nucleus is a zone of densely granular material, the nuclear cap $(N C)$, and embedded in its periphery are the mitochondria $(M)$. Between the nuclear cap and the cell membrane is a cytoplasmic zone containing a few Golgi dictyosomes $(D)$, some short profiles of endoplasmic reticulum $(E R)$ and a few membrane-bounded dark granules $(d g)$. This cytoplasmic zone has a mottled appearance. $\times 32,500(10,000 \times 3 \cdot 25)$. Pl. 2833 .

\section{Plate 5}

Figs. 6, 7. $N$. profusa. The fibrous body in longitudinal and transverse section, showing structural details. $\times 80,000(40,000 \times 2)$. Pl. 7895,7893 .

Fig. 8. N. profusa. Detail of transverse sections of flagella and their surrounding spongy ground material. $\times 60,000(30,000 \times 2)$. Pl. 7897.

* This and similar numbers attached to the figure explanations refer to the numbers of the photographic plates stored in the electron-microscope laboratory, Botany School, University of Melbourne. 